\title{
Pre-mRNA splicing alters mRNP composition: evidence for stable association of proteins at exon-exon junctions
}

\author{
Hervé Le Hir, ${ }^{1,2}$ Melissa J. Moore, ${ }^{2,3}$ and Lynne E. Maquat ${ }^{1,3}$ \\ ${ }^{1}$ Department of Cancer Genetics, Roswell Park Cancer Institute, Buffalo, New York 14263 USA; ${ }^{2}$ Department \\ of Biochemistry, Howard Hughes Medical Institute/Brandeis University, Waltham, Massachusetts 02454 USA
}

\begin{abstract}
We provide direct evidence that pre-mRNA splicing alters mRNP protein composition. Using a novel in vitro cross-linking approach, we detected several proteins that associate with mRNA exon-exon junctions only as a consequence of splicing. Immunoprecipitation experiments suggested that these proteins are part of a tight complex around the junction. Two were identified as SRm160, a nuclear matrix-associated splicing coactivator, and hPrp8p, a core component of U5 snRNP and spliceosomes. Glycerol gradient fractionation showed that a subset of these proteins remain associated with mRNA after its release from the spliceosome. These results demonstrate that the spliceosome can leave behind signature proteins at exon-exon junctions. Such proteins could influence downstream metabolic events in vivo such as mRNA transport, translation, and nonsense-mediated decay.
\end{abstract}

[Key Words: mRNP composition; pre-mRNA splicing; RNA-protein cross-linking; exon-exon junctions]

Received January 26, 2000; revised version accepted March 23, 2000.

Eukaryotic mRNAs are generated by a series of metabolic events including transcription, capping, splicing, and polyadenylation. Once made, mRNAs are transported to the cytoplasm where they undergo translation and, ultimately, decay. It is becoming increasingly clear that all of these metabolic steps are mechanistically linked in intact cells. For example, recent evidence suggests that the carboxy-terminal domain (CTD) of RNA polymerase II delivers proteins required for capping, splicing, and polyadenylation to the nascent transcript in vivo (Cho et al. 1997; McCracken et al. 1997a,b; Misteli and Spector 1999) and enhances splicing and polyadenylation in vitro (Hirose and Manley 1998; Hirose et al. 1999). Moreover, the nature of the promotor can affect alternative splicing patterns of transcripts (Cramer et al. 1999|. Also, proteins acquired in the nucleus are essential for proper localization of certain mRNAs in the cytoplasm (Lall et al. 1999).

The action of spliceosomes also can influence downstream mRNA metabolism. The presence and position of pre-mRNA introns can affect the efficiency of mRNA transport (Chang and Sharp 1989; Legrain and Rosbash 1989; Pasquinelli et al. 1997; Saavedra et al. 1997; Luo and Reed 1999), the efficiency of mRNA translation

${ }^{3}$ Corresponding authors.

E-MAIL mmoore@brandeis.edu; FAX (781) 736-2337.

E-MAIL maquat@sc3101.med.buffalo.edu; FAX (716) 845-8449.
(Matsumoto et al. 1998), and the rate of mRNA decay (Maquat 1995, 1996; Li et al. 1997; Hentze and Kulozik 1999|. Studies of nonsense-mediated mRNA decay indicate that mammalian cells can distinguish authentic from premature stop codons by their positions relative to the $3^{\prime}$-most exon-exon junction position in mRNA (Cheng et al. 1994; Carter et al. 1996; Nagy and Maquat 1998; Thermann et al. 1998; Zhang et al. 1998a,b).

The most probable means by which pre-mRNA splicing influences subsequent mRNA metabolism is by altering the structure of the messenger ribonucleoprotein particle (mRNP) (Nakielny and Dreyfuss 1997; Izaurralde and Adam 1998; Luo and Reed 1999). Such alterations could consist of covalent nucleotide modifications (Rottman et al. 1994) or noncovalent associations of specific proteins, either of which could stay with an mRNP throughout all or a portion of its lifetime. In fact, Luo and Reed (1999) demonstrated recently that an mRNP generated by splicing in vitro has altered mobility in native gels and is exported more rapidly and efficiently from Xenopus laevis nuclei than an mRNP not generated by splicing. A number of proteins known to be involved in pre-mRNA splicing, such as hnRNP Al (Dreyfuss et al. 1993; Nakielny and Dreyfuss 1997) and a subset of the SR splicing factors (Cáceres et al. 1998), shuttle between the nucleus and cytoplasm, making them potential mRNP components. HnRNP A1 clearly functions in mRNA export (Izaurralde et al. 1997), and 
electron microscope tomography has shown that an hnRNP A1-related protein accompanies Balbiani ring granules, giant mRNPs of the dipteran Chironomus tentans, through nuclear pores and into cytoplasmic polysomes (Visa et al. 1996). However, despite its demonstrated importance, the extent to which mRNP composition is altered by splicing is currently unknown.

We report direct evidence that pre-mRNA splicing alters mRNP protein composition. We employed a new in vitro cross-linking strategy designed to identify proteins left behind by the splicing machinery specifically at mRNA exon-exon junctions. Dependent on the nature of the cross-linker, the position of the cross-linker relative to the exon-exon junction and the pre-mRNA sequence, we observed at least four different proteins that cross-link only to mRNAs generated by splicing in HeLacell nuclear extract. Immunoprecipitations suggested that these four proteins are part of a tight complex around the exon-exon junction. Two of the proteins were identified as SRm160, a nuclear matrix-associated splicing coactivator subunit, and hPrp8p, a highly conserved U5 snRNP protein. Glycerol gradient fractionation indicated that most of the proteins that crosslinked in a splicing-dependent manner remain associated with mRNA after its release from the spliceosome. These data provide a new view of the dynamic nature of protein-RNA interactions at exon-exon junctions after splicing and identify proteins that might influence subsequent mRNA fate.

\section{Results}

\section{Cross-linking strategy}

To identify proteins associated with mRNA specifically as a consequence of splicing, we constructed single intron-containing pre-mRNAs having two site-specific modifications: a photoreactive group near the intronproximal end of one exon, and a single ${ }^{32} \mathrm{P}$ at or near the opposite intron-exon boundary. In vitro splicing of such pre-mRNAs in HeLa-cell nuclear extract juxtaposes both groups at the exon-exon junction in the mRNA product (Fig. 1, right). After irradiation at a wavelength appropriate for the photoreactive group followed by ribonuclease treatment and then electrophoresis through a denaturing gel, only proteins attached to the cross-linkable moiety at the exon-exon junction, and therefore associated with the ${ }^{32} \mathrm{P}$, are detectable by autoradiography.

The first substrate we prepared was PIP:E1(B) premRNA, a derivative of PIP.85B pre-mRNA /Query et al. 1994) that contained a benzophenone moiety (B) (MacMillan et al. 1994; Moore and Query 1998) at the penultimate nucleotide of exon 1 (E1) and a single ${ }^{32} \mathrm{P}$ at the beginning of E2 (Fig. 1, right; see Materials and Methods for sequence and details). We also synthesized two controls: the corresponding mRNA, PIP:E1(B) mRNA (Fig. 1, left), and a control PIP:E1(B) pre-mRNA (Fig. 1, center), identical to experimental PIP:E1(B) pre-mRNA except that the ${ }^{32} \mathrm{P}$ was positioned at the $5^{\prime}$-splice site. The control mRNA allowed for identification of proteins that

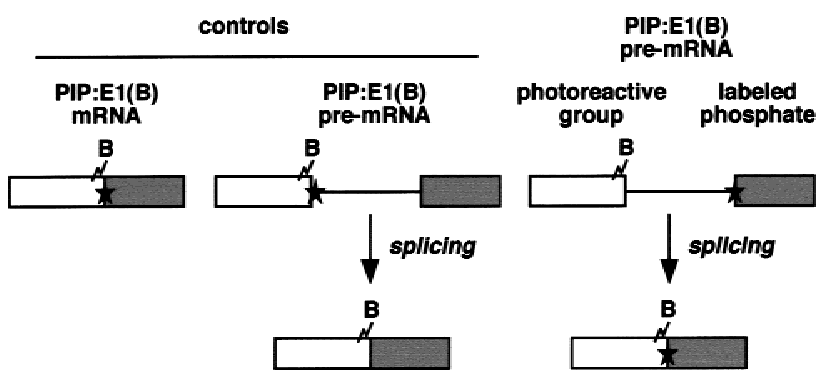

Figure 1. Schematic structures of site-specifically modified PIP:E1(B) RNAs. The experimental pre-mRNA (right) contained a benzophenone (B) at the penultimate nucleotide of exon 1 (E1, open box) and a single ${ }^{32} \mathrm{P}$ (star) at the beginning of exon 2 (shaded box). Control mRNA (left) was structurally identical to the spliced product of experimental pre-mRNA. Control premRNA (center) was identical to experimental pre-mRNA except that the ${ }^{32} \mathrm{P}$ was positioned at the $5^{\prime}$ splice site.

interact with the benzophenone independent of splicing. The control pre-mRNA permitted identification of proteins that interact with the benzophenone only before lariat formation, because in this construct the benzophenone and ${ }^{32} \mathrm{P}$ became separated during the first step of splicing and, therefore, were not juxtaposed in spliced mRNA.

\section{Splicing and cross-linking of modified RNAs}

To determine splicing kinetics and spliced product stability, each benzophenone-containing RNA was incubated under splicing conditions in HeLa-cell nuclear extract (Fig. 2A). Both pre-mRNAs spliced to similar levels, with splicing intermediates evident after $30 \mathrm{~min}$ and little additional product accumulation after $90 \mathrm{~min}$ (Fig. 2A, lanes 6-15). Control mRNA was degraded significantly over the course of the incubation (Fig. 2A, lanes 1-5). This facilitated differentiation of proteins that cross-link independent of splicing from those that crosslink dependent on splicing because the amount of mRNA that was or was not generated by splicing was comparable at both 90 and $120 \mathrm{~min}$ (Fig. 2A, cf. lanes 4 and 5 with 14 and 15). Neither splicing efficiency nor RNA stability was affected by the presence of the photoreactive group (data not shown; MacMillan et al. 1994).

To induce cross-links, each splicing reaction was incubated under splicing conditions $\left(30^{\circ} \mathrm{C}\right)$ for 0,45 , or 90 min and then irradiated with a 302-nm lamp for $20 \mathrm{~min}$ on ice $\left(4^{\circ} \mathrm{C}\right)$. No additional spliced product accumulated during the $4^{\circ} \mathrm{C}$ incubations, indicating that splicing was not ongoing during the period of UV irradiation /data not shown). Samples were subsequently treated with RNase A and analyzed by SDS-PAGE (Fig. 2B). Numerous labeled bands were observed with all three RNAs. Because no cross-linking was observed when the reactions were treated with proteinase $\mathrm{K}$ (Fig. 2B, lanes 4,9,14) or when RNAs lacked a benzophenone moiety [Fig. 2B, lanes $5,10,15$; data not shown; except in lane 10, where the low level $(<10 \%)$ of $254-n m$ light from the 302-nm lamp was 
A
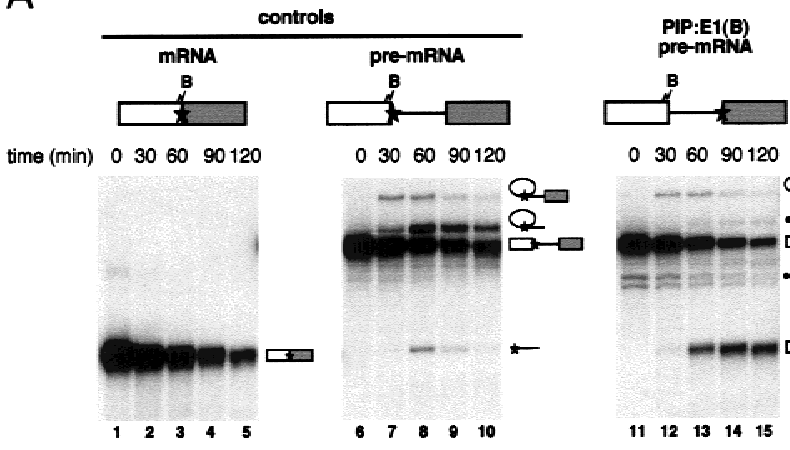

0306090120

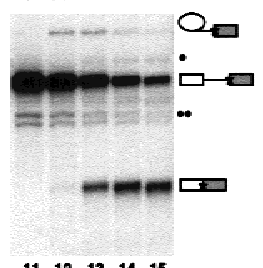

B

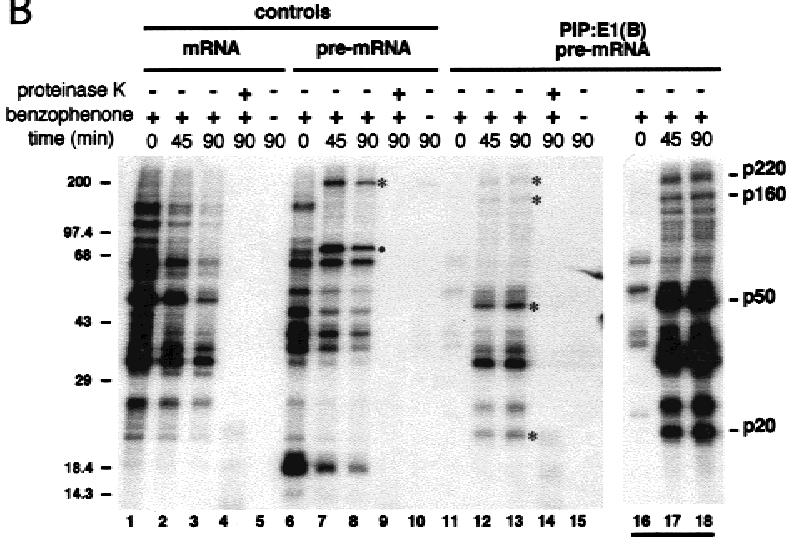

C

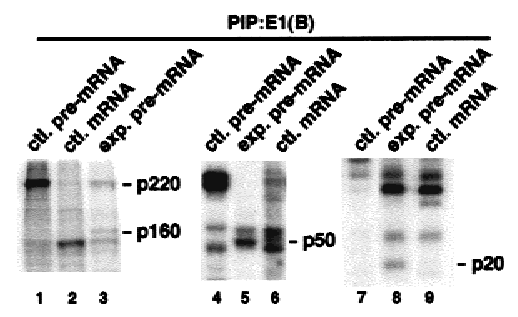

D

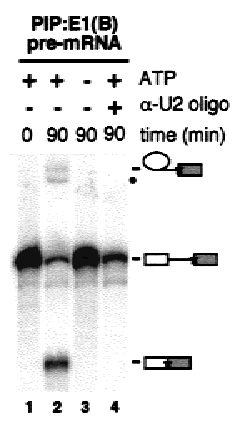

E

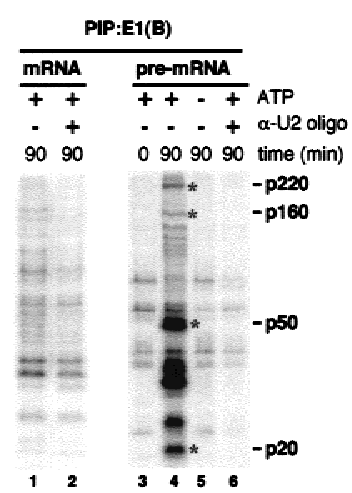

Figure 2. Splicing and cross-linking of benzophenone-containing PIP:E1(B) RNAs. (A) Splicing time courses. RNAs were incubated under splicing conditions for times indicated and separated by denaturing PAGE. Substrate and product structures are indicated above and to the right of each panel. Because all constructs contained only one ${ }^{32} \mathrm{P}$ label (star), only a subset of splicing products are detectable. The small amount of RNA of similar mobility to mRNA in lanes $8-10$ is debranched intron; this species contains label only when generated from control pre-mRNA. Species likely generated by exonucleolytic digestion of the lariat intron-exon 2 (Moore and Sharp 1992) (•) and four-way RNA ligation intermediates that copurified with full-length pre-mRNA $(\bullet \bullet)$ are indicated. (B) Protein cross-linking. After incubation under splicing conditions for times indicated, samples were irradiated on ice at $302 \mathrm{~nm}$ and digested with RNase A. Reactions in lanes 4, 9, and 14 were treated with proteinase K after cross-linking; RNAs in lanes 5, 10, and 15 were subjected to splicing and cross-linking but contained no benzophenone. Lanes 16-18 are longer exposures of lanes 11-13. Molecular mass standards $(\mathrm{kD})$ and apparent molecular masses of proteins that cross-linked in a splicing-dependent manner $(\star)$ are indicated to the left and right, respectively. $(\bullet)$ indicates position of the $\sim 70-\mathrm{kD}$ protein discussed in the text. $(C)$ Side-by-side comparisons of protein cross-linking patterns. RNAs [(ctl) control; (exp) experimental] were incubated under splicing conditions for 90 min, UV irradiated, and RNase A digested. Cross-linked proteins were separated in 7.5\% (lanes 1-3), 10\% (lanes 4-6), or 16\% (lanes 7-9) denaturating polyacrylamide gels. Proteins that cross-link in a splicing dependent manner are indicated. $(D, E)$ Dependence of crosslinks on splicing. The indicated RNAs were incubated under splicing conditions for times shown and irradiated as in $B$. As specified, splicing was inhibited by ATP omission (-ATP) or blocking U2 snRNA with a complementary 2'-O-methyl oligonucleotide $(+\alpha-\mathrm{U} 2$ oligonucleotide). (D) RNAs; $(E)$ cross-linked proteins. $\bullet$ and $\star$ are as in $A$ and $B$, respectively.

sufficient to cross-link a small amount of a $220-\mathrm{kD}$ protein to the $5^{\prime}$ splice site (see below)], bands detected in other reactions represented proteins specifically crosslinked to the photoreactive group.

Multiple proteins cross-linked to the experimental PIP:E1(B) RNA after 45 and 90 min of splicing, times by which both modifications were juxtaposed at the mRNA exon-exon junction (Fig. 2B, lanes 12,13). The pattern of cross-linked proteins was the same regardless of whether RNase treatment was performed before protein denaturation or after boiling samples in the presence of $0.5 \%$ SDS (data not shown). However, the majority of these proteins were nonspecific because they also cross-linked to control mRNA, control pre-mRNA, or both. It should be noted that similar proportions of nonspecific protein cross-links have also been observed by others when highly reactive photo-cross-linking moieties, such as benzophenone, were employed with no affinity purification step after cross-linking (Wyatt et al. 1992; MacMillan et al. 1994; Moore and Query 1998). Nonetheless, careful comparison of the pattern obtained with or without splicing revealed four proteins, with apparent molecular masses of $\sim 220,160,50$, and $20 \mathrm{kD}$, that clearly cross-linked in a splicing-dependent manner [Fig. 2B, bands marked with an asterisk in lanes 11-13 and 16-18 (darker exposure)]. These proteins did not cross-link to 
control mRNA at any point (Fig. 2B, lanes 1-3) or to experimental RNA prior to spliceosome assembly (Fig. 2B, lanes 11,16$)$. Polyacrylamide gels of $7.5 \%, 10 \%$, and $16 \%$ which allowed for greater separation in the $>150$-, $50-$, and $20-\mathrm{kD}$ ranges, respectively, corroborated these conclusions (Fig. 2C). Moreover, ${ }^{32} \mathrm{P}$ labeling of the specific proteins increased with longer splicing incubations, as would be expected for proteins that interact with the mRNA-spliced product (Fig. 2B, lanes 12,13; data not shown). When splicing of experimental pre-mRNA was inhibited by ATP omission (Fig. 2D, lane 3) or blocking U2 snRNA function with a 2'-O-methyl oligonucleotide complementary to the branch site binding region (Fig. 2D, lane 4), all four specific cross-links disappeared (Fig. $2 \mathrm{E}$, lanes 5 and 6, respectively), additionally confirming their dependence on splicing. However, as expected, the cross-linking pattern observed with the mRNA control did not change significantly when U2 snRNA function was blocked (Fig. 2E, lanes 1,2).

A $220-\mathrm{kD}$ protein also interacted with the $5^{\prime}$ splice site prior to lariat formation but dependent on spliceosome assembly (Fig. 2B, cf. lane 6 with lanes 7 and 8; data not shown), as did a protein of approximately $70 \mathrm{kD}$ (band marked with a solid circle in Fig. 2B, lanes 7,8). As would be expected of proteins interacting with the photoreactive group before the first step of splicing, the extent of p220 and p70 cross-linking to control pre-mRNA decreased over time as the ${ }^{32} \mathrm{P}$ label became separated from the benzophenone by $5^{\prime}$ splice site cleavage (Fig. 2B, lanes 7,8; data not shown).

Taken together, the above results demonstrate clearly that the protein cross-linking pattern around the exonexon junction is different for an mRNA generated by splicing and one not undergoing this process. For PIP:E1(B) mRNA, four proteins with mobilities of $\sim 220$, 160,50 , and $20 \mathrm{kD}$ cross-linked to the exon-exon junction specifically as a consequence of splicing.

\section{Immunoprecipitation of cross-linked proteins}

With the aims of separating the proteins that crosslinked dependent on splicing from those that crosslinked nonspecifically, as well as identifying the specific proteins, we performed a series of immunoprecipitations (IPs). Initially, we employed two monoclonal antibodies (mAbs), NM4 and B1C8, which had been shown previously to preferentially coimmunoprecipitate exon-containing RNA species, including the mRNA product, from in vitro splicing reactions (Blencowe et al. 1995). NM4 recognizes the SR-related, nuclear matrix splicing coactivator subunits SRm300 and SRm160 (Blencowe et al. 1998; Eldridge et al. 1999) and most of the prototypic SR protein splicing factors (Zahler et al. 1992; Blencowe et al. 1995), whereas B1C8 specifically recognizes SRm160 (Blencowe et al. 1998).

Splicing reactions containing either experimental or control PIP:E1(B) RNAs were immunoprecipitated after UV irradiation. To examine the extent to which the IP pattern was dependent on intact RNA, RNase treatment was performed either before or after IP. RNase treatment prior to IP would be expected to eliminate any proteins complexed with the mAb epitope only by virtue of being bound to the same RNA. When mAb NM4 was employed and RNase treatment followed IP, numerous cross-linked proteins were precipitated from all three reactions (Fig. 3A, lanes 2,6,10). However, when RNase treatment preceded the IP, all four proteins that crosslinked to experimental pre-mRNA in a splicing-dependent manner were efficiently precipitated, whereas other cross-linked proteins were not (Fig. 3A, cf. lane 11 with lanes 9 and 10). Moreover, the relative intensities of the four splicing-dependent cross-links were not affected by IP. No proteins that cross-linked to control mRNA were precipitated when RNase treatment preceded the IP (Fig. 3A, lane 3), and only the splicing-dependent 220- and $70-\mathrm{kD}$ proteins that cross-linked to control pre-mRNA were precipitated under these conditions (Fig. 3A, lane 7).

The simplest interpretation of the above results is that the four proteins that cross-link to the PIP:E1(B) exonexon junction dependent on splicing form a tight complex that is stable to RNase digestion, and the complex contains at least one protein bearing an NM4 epitope. However, the possibility that the nature of the complex varies between mRNA molecules so that individual molecules are bound by at least one protein bearing an NM4 epitope and any or all of the remaining three proteins cannot be discounted. Remarkably, IPs performed on experimental pre-mRNA using mAb B1C8 after RNase treatment, although less efficient overall, yielded a very similar pattern of precipitated proteins to that obtained with mAb NM4 (Fig. 3B, cf. lanes 4 and 7). Because B1C8 is specific for SRm160, SRm160 must be a component of the protein complex at the exon-exon junction. To test whether the cross-linked 160-kD protein was SRm160, IPs were performed next with the two mAbs after both RNase digestion and protein denaturation. This reduced significantly the number of cross-links observed (Fig. 3B, lanes 5-6,8-9). Under the most stringent denaturing conditions, the only splicing-dependent cross-linked protein immunoprecipitated with either $\mathrm{mAb}$ was the $160-\mathrm{kD}$ protein (Fig. 3B, lanes 6,9), identifying it as SRm160.

Proteins with apparent molecular masses of $\sim 55,40$, and $25 \mathrm{kD}$ that cross-linked independent of splicing were also immunoprecipitated by mAb NM4 after stringent protein denaturation (Fig. 3B, lane 6). This raised the possibility that these proteins were SRp55, SRp40, and either SRp30 or SRp20. We have confirmed that the 25$\mathrm{kD}$ protein is SRp20, since SRp20 antiserum (Neugebauer and Roth 1997) immunoprecipitated the ca. 25-kD protein, and this protein comigrated with SRp20 when assayed by Western blot hybridization (data not shown).

Because the $220-\mathrm{kD}$ protein was not immunoprecipitated by mAb NM4 after protein denaturation, it was unlikely SRm300 (Fig. 3B, lane 6). Another possibility was hPrp8p, a 279-kD component of U5 snRNP (Luo et al. 1999), because a similar-sized protein also crosslinked to the $5^{\prime}$ splice site after spliceosome assembly (Fig. 2B, lanes 7,8), and other studies have shown that Prp8p cross-links in the vicinity of both the $5^{\prime}$ splice site 
A

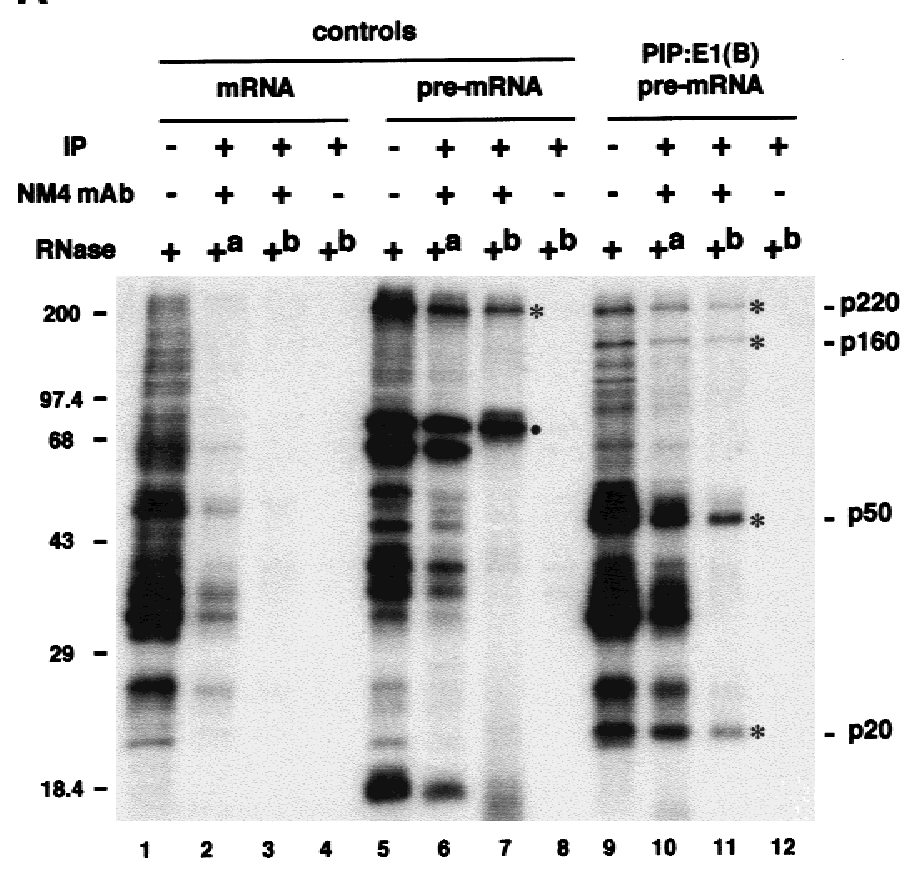

C

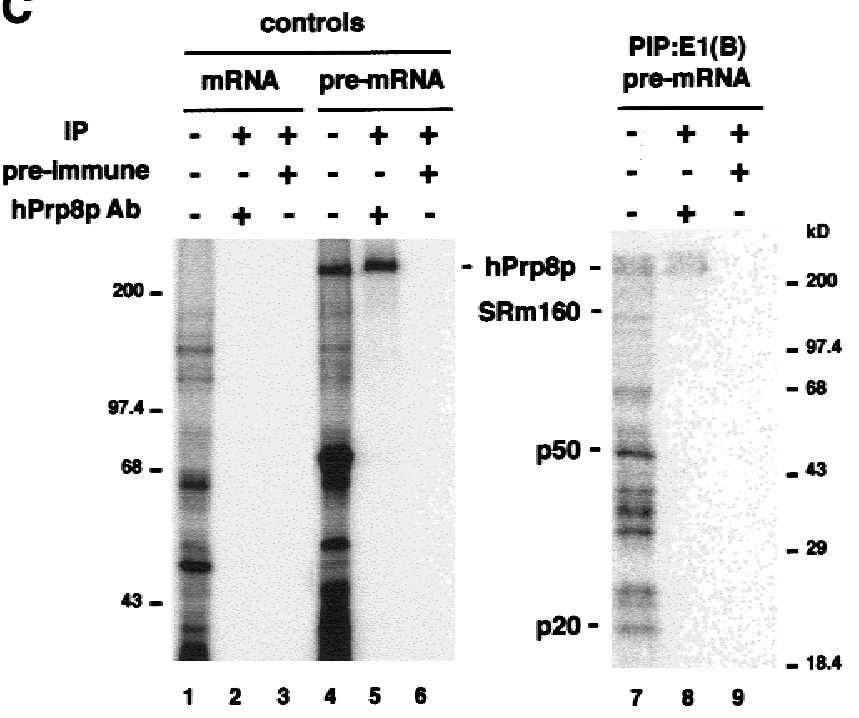

B

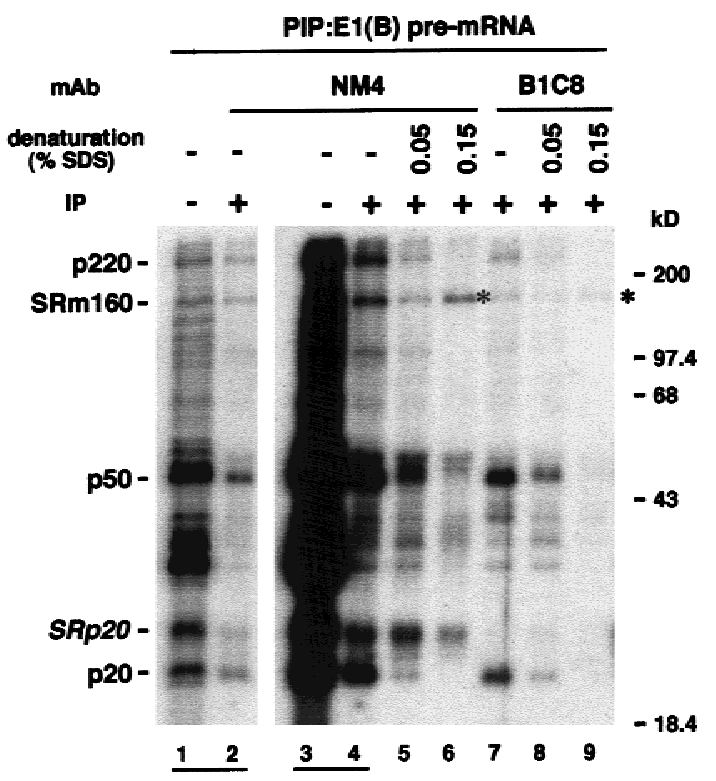

Figure 3. IP of proteins cross-linked to PIP:E1(B) RNAs. (A) IP of native complexes with mAb NM4. RNAs were incubated under splicing conditions for $90 \mathrm{~min}$, irradiated, and treated with RNase without IP $(+)$ (lanes 1, 5, and 9), treated with RNase after $\left(+^{\mathrm{a}}\right)$ IP $($ lanes $2,6,10)$, or treated with RNase before $\left(+{ }^{\mathrm{b}}\right)$ IP (lanes $\left.3,4,7,8,11,12\right)$. IPs in lanes 4,8 , and 12 contained no antibody. $(\bullet)$ Indicates position of the $\sim 70-\mathrm{kD}$ protein discussed in text. (B) IP of native and denatured proteins with mAb NM4 or B1C8. Experimental pre-mRNA was spliced for $90 \mathrm{~min}$, irradiated, and treated with RNase. Lanes 1 and 2 are shorter exposures of lanes 3 and 4. Samples in lanes 1 and 3 were not further purified. IPs with either mAb NM4 (lanes 2,4-6) or mAb B1C8 (lanes 7-9) were performed without prior protein denaturation $(-;$ lanes $2,4,7)$ or after boiling in either $0.05 \%$ SDS (lanes 5,8$)$ or $0.15 \%$ SDS (lanes 6,9). (C) IP of denatured proteins with hPrp8p antiserum or preimmune serum. After incubation of RNAs under splicing conditions for $90 \mathrm{~min}$, irradiation, and RNase treatment, proteins were denatured by boiling in $0.25 \%$ SDS. Samples in lanes 1, 4, and 7 were not further purified. IPs were performed with either hPrp8p antiserum (lanes 2,5,8) or preimmune serum (lanes 3,6,9).

In summary, the IP experiments indicate that proteins that cross-link to the PIP:E1(B) mRNA exon-exon junction dependent on splicing are part of a tight RNaseresistant complex. Additionally, two of these proteins are SRm 160 and hPrp8p. The splicing-dependent $\sim 50$ and $20 \mathrm{kD}$ proteins remain unidentified.

\section{Cross-linking to other exon-exon junctions}

To determine whether the pattern of splicing-dependent cross-linked proteins obtained with PIP:E1(B) pre-mRNA was unique to that construct or more general, we undertook additional cross-linking analyses with two other experimental pre-mRNAs, PIP:E1(S) and PIP:E2(S), and 
appropriate controls (Fig. 4). Relative to PIP:E1(B), both new constructs contained a different sequence at the $3^{\prime}$ end of exon 1, and a different photoreactive moiety, 4-thio-dU (S). Compared to the benzophenone moiety, which was attached to the RNA via a long linker arm (MacMillan et al. 1994), 4-thio-dU has a much shorter reach and should therefore only react with proteins in close proximity to the RNA (Sontheimer 1994; Moore and Query 1998). PIP:E1(S) and PIP:E2(S) differed in the position of the 4-thio-dU, which was located at the $3^{\prime}$ end of exon 1 (E1) or the $5^{\prime}$ end of exon 2 (E2), respectively (Fig. 4A).

Both new pre-mRNAs spliced with similar kinetics to PIP:E1(B) pre-mRNA (data not shown). Like PIP:E1(B),

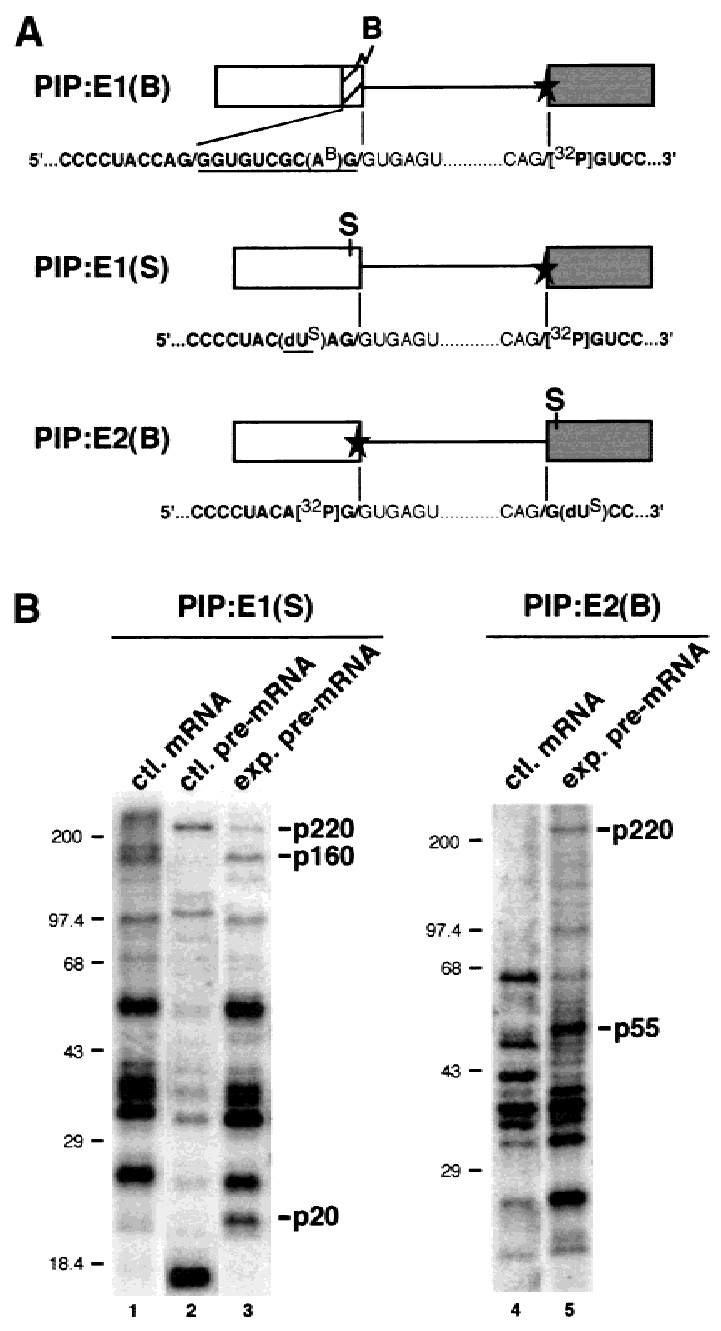

Figure 4. Protein cross-linking to 4-thio-dU-containing PIP RNAs. (A) Schematic structures of the three experimental PIP pre-mRNAs and sequences around the $5^{\prime}$ and $3^{\prime}$ splice sites. (Star) Positions of benzophenone (B), 4-thio-dU (S) and ${ }^{32} \mathrm{P}$. Underlined nucleotides correspond to those differing between constructs. $(B)$ RNAs as indicated were incubated under splicing conditions for $90 \mathrm{~min}$, UV irradiated, and treated with either RNase A or T1 (see Materials and Methods). Proteins that crosslinked in a splicing-dependent manner are specified to the right of each panel. the pattern of proteins that cross-linked to the exonexon junctions of both PIP:E1(S) and PIP:E2(S) mRNAs was dependent on whether or not the mRNA was generated by splicing (Fig. 4B). Overall, the cross-linking patterns observed with experimental and control PIP:E1(S) RNAs were quite similar to those obtained for their respective PIP:E1(B) constructs (cf. Fig. 4B, lanes 1-3, with Figs. 2 and 3). Proteins migrating with apparent molecular weights of $\sim 220,160$, and $20 \mathrm{kD}$ whose cross-linking depended on splicing were clearly observable (Fig. 4B, cf. lane 3 with lanes 1 and 2). Because the 220-kD protein also cross-linked to control PIP:E1(S) pre-mRNA (Fig. 4B, lane 2), this protein is most likely hPrp8p. However, there was no discernible protein of $50 \mathrm{kD}$ that specifically cross-linked to experimental PIP:E1(S) RNA. It is possible that the $50-\mathrm{kD}$ protein that cross-linked to experimental PIP:E1(B) RNA is relatively distant from the RNA or is sequence-specific. When the 4-thio-dU was moved to exon 2 [PIP:E2(S)], the overall cross-linking pattern was noticeably different. Although a splicing-specific p220 was still observed, another splicing-dependent protein migrated at ca. $55 \mathrm{kD}$.

These results indicate that splicing alters the complement of proteins associated with exon-exon junctions regardless of the nature of the photoreactive group, the position of this group relative to the exon-exon junction, or the exact sequence of the 5' exon, even though changing the position or the nature of the photoreactive group can affect exactly which proteins are detected by this method.

\section{Glycerol gradient fractionation}

Although the experiments presented above identified proteins that cross-link to mRNA specifically as a consequence of splicing, they did not reveal which, if any, remain associated with mRNA after its release from the spliceosome. Previous studies have shown that mRNPs can be separated from spliceosomes by glycerol gradient fractionation (Cheng and Abelson 1987; Konarska and Sharp 1987). To determine the sedimentation profile of PIP RNAs and cross-linked proteins, experimental PIP:E1(B) pre-mRNA was incubated under splicing conditions for $2 \mathrm{hr}$, UV irradiated, and fractionated in a $10 \%-30 \%$ glycerol gradient. Fractions were then divided and the RNAs and cross-linked proteins analyzed in appropriate denaturing gels (Fig. 5A). Spliceosomes sedimented toward the bottom of the gradient (fractions 8-15) and were defined by the presence of both premRNA and lariat intermediate, a product of the first step of splicing (Fig. 5A, bottom). The mRNA migrated as a broad peak toward the top of the gradient (fractions 3-8), indicating that nearly all of it had been released from the spliceosome. Notably, two of the mRNA-containing fractions were nearly free of both pre-mRNA and splicing intermediates (fractions 3 and 4).

All proteins that cross-linked independent of splicing cosedimented with mRNA. Cross-linked SRm160, p50, and p20 also cosedimented with mRNA. In contrast, cross-linked hPrp8p seemed to sediment in two peaks of 
A

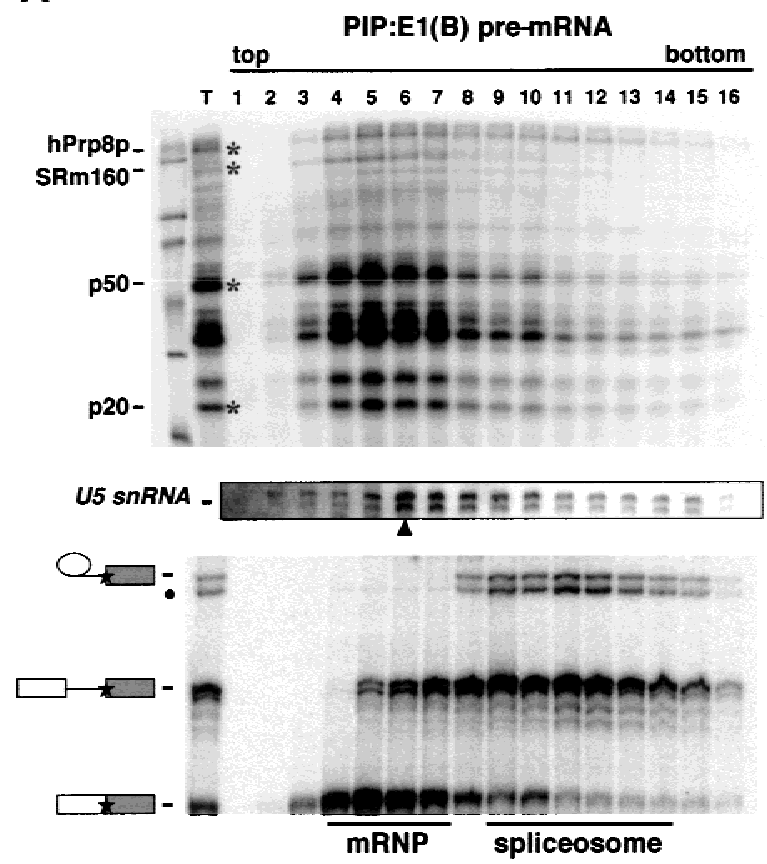

B
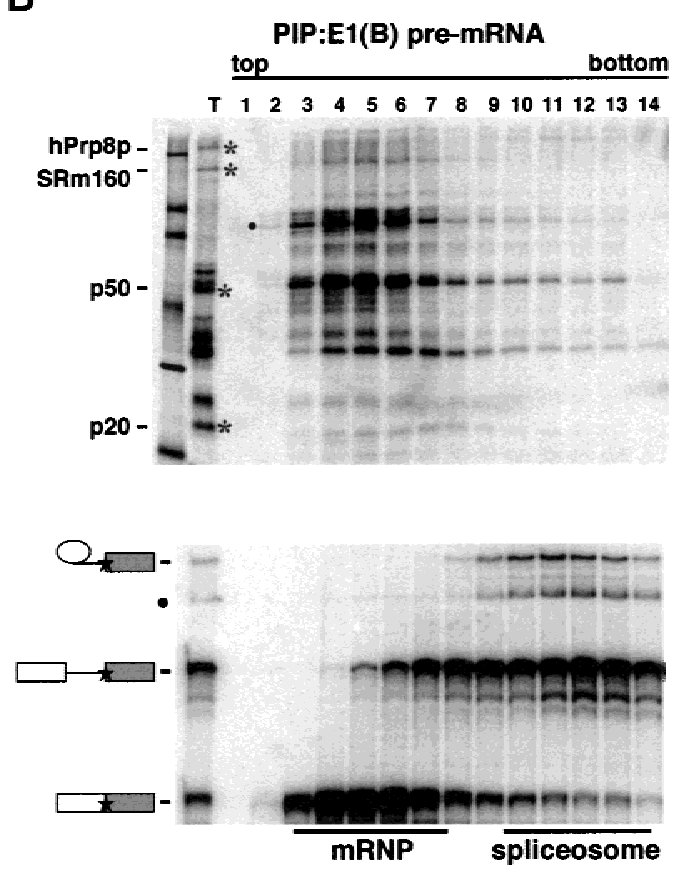

Figure 5. Glycerol gradient fractionation. (A) Profile of proteins cross-linked to experimental PIP:E1(B) pre-mRNA after 2 hr of splicing, UV irradiation, and fractionation in a 10\%-30\% glycerol gradient (top panel). RNAs extracted from a portion of each fraction were analyzed in a denaturing RNA gel (bottom panel) to reveal the sedimentation profiles of mRNP (mRNA) and spliceosomes (lariat-exon 2). (Bars) Positions of mRNP and spliceosomes. Lane $\mathrm{T}$ (total) is an aliquot of the same reaction mixture before fractionation. Extracted RNAs were also analyzed by Northern blotting using a U5 snRNA specific probe (middle panel). (Arrow) Peak position of U5 snRNA. $(B)$ Same as $A$, except that UV irradiation was performed after density sedimentation and U5 snRNA was not analyzed. Species likely generated by exonucleolytic degradation of the lariat intron-exon 2 (Moore and Sharp 1992) are indicated (•) in the lower panels of both $A$ and $B$.

approximately equal intensity, one comigrating with released mRNA and another with intact spliceosomes. This suggests that only a portion of mRNA that was cross-linked to hPrp8p was released from the spliceosome. Furthermore, because only a small fraction of total mRNA cosedimented with spliceosomes, cross-linking of hPrp8p may be significantly more efficient prior to mRNA release. Interestingly, however, Northern blot analysis demonstrated that the peak of cross-linked $h$ Prp8p that did cofractionate with released mRNA sedimented at a slightly lower velocity than the peak of U5 snRNA (Fig. 5A, cf. U5 snRNA, mRNA, and cross-linked $\mathrm{hPrp} 8 \mathrm{p})$. This raised the intriguing possibility that hPrp8p cross-linked to released PIP mRNA was not associated with fully intact U5 snRNP.

In theory, cross-linked proteins cosedimenting with released mRNA could be true components of PIP mRNP or could be present only because their association with the mRNA had been artificially stabilized by cross-linking. This issue was particularly pertinent to hPrp8p because U5 snRNA has been shown to remain associated with the spliced intron product in a spliceosome-sized complex after mRNA release (Cheng and Abelson 1987; Konarska and Sharp 1987). To differentiate between these possibilities, we repeated the sedimentation analysis except that cross-linking was performed after sedimentation (Fig. 5B). Under these conditions, cross-linked
hPrp8p exhibited a bimodal distribution similar to that observed in Figure 5A. Similarly, cross-linked SRm160 and p50 cosedimented with mRNA as above. However, the distribution of cross-linked p20 was somewhat altered by the fractionation procedure, with its peak intensity moving to slightly higher velocity fractions. This suggests that p20 is not associated as stably with spliceosome-released mRNA as the other splicing-specific proteins. That protein-RNA associations could change within the gradient was confirmed by the presence of a strong, but previously unobserved, cross-link evident at ca. $75 \mathrm{kD}$ (Fig. 5B, dot). Thus, association of PIP mRNA with a previously undetected protein became apparent during sedimentation.

Taken together, results obtained by glycerol gradient fractionation indicate that $\mathrm{hPrp} 8 \mathrm{p}, \mathrm{SRm} 160$, and $\mathrm{p} 50$ are all genuine components of PIP mRNP produced in vitro.

\section{Discussion}

We provide evidence that some of the proteins that associate with mRNA exon-exon junctions in vitro do so only as a consequence of splicing. Several of these proteins form a stable complex that survives RNase treatment. Below we discuss how the identified proteins relate to the process of splicing and the current picture of mRNP structure and function. 
Properties of proteins associated with exon-exon junctions specifically as a consequence of splicing

We observed four proteins that cross-linked to the exonexon junction of PIP:E1(B) mRNA in a splicing-dependent manner. So far, we have identified two of these as SRm160 and hPrp8p. SRm160 is a nuclear matrix antigen (Blencowe et al. 1995, 1998) that contains multiple RS repeats but, unlike prototypic SR proteins (Zahler et al. 1992), lacks an RNA recognition motif (RRM). However, SRm160 had not been shown previously to crosslink to RNA (Blencowe et al. 1998). Instead, previous studies showed that SRm160 forms a complex with another nuclear matrix antigen, SRm300, and this complex serves to promote splicing through interactions with SR protein family members. Notably, association of SRm160/300 with specific pre-mRNAs is dependent on SR proteins and U1 snRNP and is stabilized by U2 snRNP (Blencowe et al. 1998; Eldridge et al. 1999). This is consistent with our results showing that SRm160 only cross-links to an exon-exon junction that has been formed by the spliceosome. Moreover, our results suggest that SRm160 becomes closely associated with exonic RNA only after splicing, because SRm160 did not cross-link to the control pre-mRNA that allowed detection of protein-RNA interactions prior to lariat formation (Fig. 2B). If the 160-kD cross-linked protein observed with experimental PIP:E1(S) RNA (Fig. 4B) is also SRm160, then it is closely associated with the mRNA and its ability to cross-link to the $5^{\prime}$ side of the exonexon junction is not highly sequence-dependent.

hPrp8p cross-linked to the $5^{\prime}$ exon both before lariat formation and after exon ligation (Fig. 2B; data not shown). It also cross-linked to the $3^{\prime}$ exon after exon ligation in the PIP:E2(S) construct (Fig. 4B). This remarkably conserved U5 snRNP protein (Hodges et al. 1995; Luo et al. 1999/ is a core component of the spliceosome that enters splicing complexes as part of the U4/U6:U5 tri-snRNP. Therefore, its association with splicing substrates, intermediates, and products requires spliceosome assembly. The many documented interactions between Prp8p and sites in both pre-mRNA and snRNAs important for the transesterification reactions implicate Prp8p as a key active site component (Reyes et al. 1996; Collins and Guthrie 1999; Siatecka et al. 1999 and references therein). Previous cross-linking studies have placed Prp8p at the 5' splice site before lariat formation, consistent with our observations with the control premRNA (Fig. 2B), as well as in the vicinity of the 3 ' splice site before exon ligation (Wyatt et al. 1992; Teigelkamp et al. 1995; Umen and Guthrie 1995; Chiara et al. 1996, 1997; Reyes et al. 1996). Our results now indicate that some of these interactions are maintained after exon ligation and can persist in the mRNP complex after spliceosome release (see below).

In our cross-linking reactions, we also observed numerous proteins that associated with the mRNA independent of splicing. So far, we have only identified one as SRp20 (Zahler et al. 1992; Neugebauer and Roth 1997). This is consistent with previous studies showing that recombinant SRp20 can bind RNA independent of other splicing components (Cavaloc et al. 1999; Schaal and Maniatis 1999).

Some splicing-dependent proteins remain associated with PIP mRNA after spliceosome release

To determine whether any of the cross-linked proteins observed here were candidates for bona fide mRNP components, we also examined their association with PIP mRNA that had been released from the spliceosome. It was established previously that mRNA release is an active process requiring ATP hydrolysis by the Prp22/ HRH1 RNA helicase (Company et al. 1991; Ohno and Shimura 1996; Schwer and Gross 1998; Wagner et al. 1998). Release occurs efficiently in HeLa-cell splicing reactions, and the resultant mRNP can be separated from spliceosomes by glycerol gradient fractionation (Konarska and Sharp 1987). Because most of the PIP:E1(B) mRNA present in splicing reactions after $2 \mathrm{hr}$ had been released from spliceosomes (Fig. 5), it seemed likely that at least some of the proteins that cross-linked to the exon-exon junction at this time were mRNP components. This was clearly true for SRm160 and p50, which cosedimented exclusively with free $\mathrm{mRNP}$ regardless of whether cross-linking was performed before or after sedimentation (Fig. 5, cf. A and B).

In contrast, cross-linked hPrp8p was detected both in fractions containing spliceosomes and in fractions containing mRNP (Fig. 5A,B). The presence of hPrp8p in mRNP was unexpected because it is known to interact directly with U5 snRNA (Dix et al. 1998), which remains bound to the spliced intron product after mRNA release (Cheng and Abelson 1987; Konarska and Sharp 1987). However, our observation that hPrp8p cross-linked to PIP mRNA even after glycerol gradient fractionation indicates that it is a component of the PIP mRNP. This mRNP is of somewhat lower density than free U5 sn$\mathrm{RNP}$, opening the possibility that hPrp $8 \mathrm{p}$ in $\mathrm{mRNP}$ is no longer associated with fully intact U5 snRNP. Interestingly, upon U5 snRNP dissociation in vitro, hPrp8p can be found in RNA-free complexes with other U5 snRNP proteins including a $200-\mathrm{kD}$ RNA helicase, a 116-kD EF-2 homolog, and a 40-kD WD-repeat-containing protein (Achsel et al. 1998). Thus, it is possible that these other proteins are also mRNP components.

\section{Evidence for a stable protein complex at the mRNA exon-exon junction}

All four proteins that cross-linked to PIP:E1(B) mRNA in a splicing-dependent manner were immunoprecipitable with mAbs NM4 and B1C8, both before and after RNase treatment (Fig. 3A,B). Among these proteins, hPrp8p does not contain an epitope recognized by these mAbs, and p50 and p20 also likely lack an appropriate epitope because they failed to be precipitated when both RNase digestion and protein denaturation preceded the IP. This suggests that all are part of a complex that remains 
bound to the exon-exon junction as a signature of splicing. The glycerol gradient fractionation results indicate that at least hPrp8p, SRm160, and p50 remain stably associated with PIP:E1(B) mRNA after its release from the spliceosome (Fig. 5A,B).

While it remains to be determined whether or not the proteins we identified here typify all mRNPs, the type of complex observed could serve as a general mark of exonexon junctions. It will now be of interest to determine how long these proteins remain associated with mRNA. Interestingly, SRm160 can be found in both nuclear and cytoplasmic fractions and can be visualized in nuclear tracks that branch and often terminate near nuclear pore complexes (J. Nickerson, pers. comm.). This suggests that SRm160 may maintain its mRNA association even after mRNA export to the cytoplasm. Identification and functional characterization of other signature proteins will help to extend our understanding of how pre-mRNA splicing influences downstream mRNA metabolic events in vivo.

\section{Materials and methods}

\section{Synthesis of doubly modified RNAs}

PIP:E1(B) experimental pre-mRNA was synthesized by splinted ligation of four separate RNA pieces (Moore and Query 1998): (1) a GpppG-capped transcript corresponding to the 5' end of E1; (2) a synthetic oligomer containing a convertible adenosine near its 3 ' end (MacMillan et al. 1994); (3) a transcript comprising the entire intron; and $(4)$ a $5^{\prime}{ }^{32} \mathrm{P}$-labeled transcript comprising E2. Each fragment is indicated within the pre-mRNA sequence below (where bold nucleotides represent exons, the asterisk specifies the convertible adenosine, underlining indicates intronic splice and branch site consensus sequences, and slashes separate the four fragments), which derived from PIP85.B (Query et al. 1994): 5'-GpppGGCGAAUUCGAGCUCACUCUCUUC CGCAUCGCUGUCUGCGAGGUACCCUACCAG/GGUGU CGC(A $\left(\mathbf{A}^{\star}\right) \mathbf{G} /$ GUGAGUAUGGAUCCCUCUAAAAGCGGGC AUGACUUCUAGAGUAGUCCAGGGUUUCCGAGGGUU UCGUCGACGAUGUCAGCUCGUCUCGAGGGUGCUGA CUGGCCUCCUUUUUCCUCCCUCCACAG $/{ }^{32}$ PGUCCUA CACAACAUACUGCAGGACAAACUCUUCG CGGUCUCU GCAUGCAAGCU-3' Following purification of full-length premRNA, benzophenone derivatization of the convertible nucleotide was performed as described previously (MacMillan et al. 1994; Moore and Query 1998). Control PIP:E1(B) pre-mRNA was generated by three-way ligation of fragments 1,2 , and a single $5^{\prime}-{ }^{32} \mathrm{P}$-labeled transcript comprising fragments 3 and 4 . Control PIP:E1(B) mRNA was synthesized by three-way ligation of fragments 1,2 , and $5^{\prime}{ }^{32}$ P-labeled fragment 4 . All three RNAs were also synthesized with an unmodified version of fragment 2 for the benzophenone-less reactions in Figure 2B.

Other experimental pre-mRNAs and corresponding controls were generated similarly. The relevant sequences around the $5^{\prime}$ and $3^{\prime}$ splice sites, as well as the position of the photoreactive group (4-thio-dU; Glen Research) and ${ }^{32} \mathrm{P}$ are indicated in Figure $4 \mathrm{~A}$ for each experimental pre-mRNA.

\section{Nuclear extracts and splicing reactions}

HeLa-cell nuclear extracts (Dignam et al. 1983) were prepared with modifications described (Abmayr et al. 1988) from cells grown by Cellex Biosciences. Splicing reactions (20 $\mu$ l) containing 10 fmoles of labeled RNA were carried out in $40 \%$ nuclear extract, $2 \mathrm{~mm} \mathrm{MgOAc} c_{2}, 20 \mathrm{~mm}$ potassium glutamate, $1 \mathrm{~mm}$ ATP, $5 \mathrm{~mm}$ creatine phosphate, and $0.05 \mathrm{mg} / \mathrm{ml}$ of $E$. coli tRNA. Following incubation at $30^{\circ} \mathrm{C}$ for times indicated, each reaction was supplemented with heparin $(0.5 \mathrm{mg} / \mathrm{ml}$ final concentration) and incubated for an additional $5 \mathrm{~min}$ at $30^{\circ} \mathrm{C}$. Splicing inhibition was accomplished by either incubating reactions for $10 \mathrm{~min}$ at $30^{\circ} \mathrm{C}$ without ATP and creatine phosphate prior to premRNA addition, or by adding $5 \mu \mathrm{M}$ of a $2^{\prime}$-O-methyl oligonucleotide (5'-AGAUACUACACUUGAUC- $\left.3^{\prime}\right)$ complementary to nucleotides 27-41 of human U2 snRNA (Luo et al. 1999) and incubating for $10 \mathrm{~min}$ at $30^{\circ} \mathrm{C}$ prior to pre-mRNA addition. For RNA analysis, reactions were quenched with 10 volumes of splicing stop buffer (100 mm Tris at pH 7.5, $10 \mathrm{~mm}$ EDTA, 1\% SDS, $150 \mathrm{~mm} \mathrm{NaCl}, 300 \mathrm{~mm} \mathrm{NaO}$ acetate), phenol/chloroform extracted and ethanol precipitated. RNAs were separated in $15 \%$ denaturing polyacrylamide gels and visualized by autoradiography or with a Molecular Dynamics PhosphorImager.

\section{Cross-linking}

Photoreactive substrates of high specific activity $(8000 \mathrm{cpm} /$ fmole) were incubated $\left(\sim 10^{4} \mathrm{cpm} /\right.$ reaction) under splicing conditions. Cross-linking was performed on ice by irradiation for 20 min with a 302 or $365 \mathrm{~nm}$ hand-held lamp (UltraViolet Products) for benzophenone- and 4-thio-dU-derivatized RNAs, respectively. Reactions were digested with either $0.1 \mathrm{mg} / \mathrm{ml}$ RNase A [Sigma; for PIP:E1(B) and PIP:E2(S) RNAs] or $1 \mathrm{U} / \mathrm{ml}$ RNase T1 [Sigma; for PIP:E1(S) RNAs] for $30 \mathrm{~min}$ at $37^{\circ} \mathrm{C}$. For RNase treatment after protein denaturation, samples were boiled for $2 \mathrm{~min}$ in the presence of $0.5 \%$ SDS prior to RNase addition. Proteinase K treatment was performed in $0.5 \%$ SDS after both cross-linking and RNase digestion by adding proteinase $\mathrm{K}$ to $1 \mathrm{mg} / \mathrm{ml}$ (Boehringer) and incubating for $5 \mathrm{~min}$ at $65^{\circ} \mathrm{C}$ and then $30 \mathrm{~min}$ at $30^{\circ} \mathrm{C}$. Cross-linked proteins were separated in SDS-16\% polyacrylamide (200:1 acrylamide:bis) gels or in SDS-7.5\% and SDS-10\% polyacrylamide (29:1 acrylamide:bis) and detected by autoradiography or PhosphorImaging. ${ }^{14} \mathrm{C}$-Labeled protein molecular weight standards (GIBCO BRL) were run as controls.

\section{Immunoprecipitations}

Antibodies were bound to protein A-Sepharose (PAS) beads (Pharmacia) via rabbit anti-mouse IgG + IgM (Pierce) for NM4, B1C8, and SRp20 antiserum, and directly to the beads for hPrp8 antiserum and preimmune serum. For IPs, $20 \mu \mathrm{l}$ of cross-linked samples were diluted with $200 \mu \mathrm{l}$ of IP100 (Luo et al. 1999) and combined with $40 \mu \mathrm{l}$ of $50 \%$ slurry PAS-bound antibodies. Samples were denatured by boiling for $2 \mathrm{~min}$ in $0.05 \%, 0.15 \%$, or $0.5 \%$ (wt $/ \mathrm{vol}$ ) SDS prior to dilution and IP, where indicated. Cross-linked proteins were bound over $3 \mathrm{hr}$ at $4^{\circ} \mathrm{C}$ with gentle mixing, after which beads were washed three times with IP100, or twice with IP150-1 M urea (Luo et al. 1999) and once with IP100 for hPrp8p IPs.

\section{Glycerol gradient analysis}

Splicing reactions $(30 \mu \mathrm{l})$ were incubated for $2 \mathrm{hr}$ at $30^{\circ} \mathrm{C}$, supplemented to $0.5 \mathrm{mg} / \mathrm{ml}$ heparin, and further incubated for 5 min at $30^{\circ} \mathrm{C}$. Reactions were cross-linked either before or after sedimentation through a $10 \%-30 \%$ glycerol gradient $(600-\mu l$ gradient containing $50 \mathrm{~mm}$ Tris-glycine at $\mathrm{pH} 8.8$ ) at 38,000 rpm for $2.5 \mathrm{hr}$ at $4^{\circ} \mathrm{C}$ in a SW55 rotor (Beckman). Gradients were manually fractionated into $16 \times 25 \mu$ l aliquots. Typically, $5 \mu \mathrm{l}$ of 
each was extracted with phenol/chloroform, ethanol precipitated, and used for RNA analyses. For Northern analysis, RNAs were separated in an $8 \%$ denaturing polyacrylamide gel, transferred to an ICN nylon membrane, and hybridized with a probe complementary to U5 snRNA (Konarska and Sharp 1987). The remainder of each fraction was treated with RNase A, and crosslinked proteins were separated and detected as described above.

\section{Acknowledgments}

We are grateful to Ben Blencowe, Karla Neugebauer, Charles Query, and Mark Roth for providing reagents as noted in the text. We thank Ben Blencowe, Karla Neugebauer, Jeff Nickerson, Charles Query and members of the Maquat and Moore laboratories for helpful discussions, and Ben Blencowe, Torben Heick-Jensen, Charles Query, Michael Rosbash, and Phillip Sharp for critical comments on the manuscript. This work was supported by U.S. Public Health Service Research grants DK 33933 (L.E.M.), a Packard Fellowship (M.J.M.), and fellowships from the Association pour la Recherche sur le Cancer and Philippe Foundation (H.L.H.).

The publication costs of this article were defrayed in part by payment of page charges. This article must therefore be hereby marked "advertisement" in accordance with 18 USC section 1734 solely to indicate this fact.

\section{References}

Abmayr, S.M., J.L. Workman, and R.G. Roeder. 1988. The pseudorabies immediate early protein stimulates in vitro transcription by facilitating TFIID: Promoter interactions. Genes \& Dev. 2: 542-553.

Achsel, T., K. Ahrens, H. Brahms, S. Teigelkamp, and R. Luhrmann. 1998. The human U5-220kD protein (hPrp8) forms a stable RNA-free complex with several U5-specific proteins, including an RNA unwindase, a homologue of ribosomal elongation factor EF-2, and a novel WD-40 protein. Mol. Cell. Biol. 18: 6756-6766.

Blencowe, B.J., R. Issner, J. Kim, P. McCaw, and P.A. Sharp. 1995. New proteins related to the Ser-Arg family of splicing factors. RNA 1: 852-865.

Blencowe, B.J., R. Issner, J.A. Nickerson, and P.A. Sharp. 1998. A coactivator of pre-mRNA splicing. Genes \& Dev. 12: $996-$ 1009.

Cáceres, J.F., G.R. Screaton, and A.R. Krainer. 1998. A specific subset of SR proteins shuttles continuously between the nucleus and the cytoplasm. Genes \& Dev. 12: 55-66.

Carter, M.S., S. Li, and M.F. Wilkinson. 1996. A splicing-dependent regulatory mechanism that detects translation signals. EMBO T. 15: 5965-5975.

Cavaloc, Y., C.F. Bourgeois, L. Kister, and J. Stevenin. 1999. The splicing factors 9G8 and SRp20 transactivate splicing through different and specific enhancers. RNA 5: 468-483.

Chang, D.D. and P.A. Sharp. 1989. Regulation by HIV Rev depends upon recognition of splice sites. Cell 59: 789-795.

Cheng, J., P. Belgrader, X. Zhou, and L.E. Maquat. 1994. Introns are cis effectors of the nonsense-codon-mediated reduction in nuclear mRNA abundance. Mol. Cell. Biol. 14: 6317-6325.

Cheng, S.C. and J. Abelson. 1987. Spliceosome assembly in yeast. Genes \& Dev. 1: 1014-1027.

Chiara, M.D., O. Gozani, M. Bennett, P. Champion-Arnaud, L. Palandjian, and R. Reed. 1996. Identification of proteins that interact with exon sequences, splice sites, and the branch- point sequence during each stage of spliceosome assembly. Mol. Cell. Biol. 16: 3317-3326.

Chiara, M.D., L. Palandjian, R. Feld-Kramer, and R. Reed. 1997. Evidence that U5 snRNP recognizes the $3^{\prime}$ splice site for catalytic step II in mammals. EMBO J. 16: 4746-4759.

Cho, E.J., T. Takagi, C.R. Moore, and S. Buratowski. 1997. mRNA capping enzyme is recruited to the transcription complex by phosphorylation of the RNA polymerase II carboxy-terminal domain. Genes \& Dev. 11:3319-3326.

Collins, C.A. and C. Guthrie. 1999. Allele-specific genetic interactions between Prp8 and RNA active site residues suggest a function for Prp8 at the catalytic core of the spliceosome. Genes \& Dev. 13: 1970-1982.

Company, M., J. Arenas, and J. Abelson. 1991. Requirement of the RNA helicase-like protein PRP22 for release of messenger RNA from spliceosomes. Nature 349: 487-493.

Cramer, P., J.F. Cáceres, D. Cazalla, S. Kadener, A.F. Muro, F.E. Baralle, and A.R. Kornblihtt. 1999. Coupling of transcription with alternative splicing: RNA pol II promoters modulate SF2/ASF and 9G8 effects on an exonic splicing enhancer. Mol. Cell 4: 251-258.

Dignam, J.D., R.M. Lebovitz, and R.D. Roeder. 1983. Accurate transcription initiation by RNA polymerase II in a soluble extract from isolated mammalian nuclei. Nucleic Acids Res. 11: 1475-1489.

Dix, I., C.S. Russell, R.T. O'Keefe, A.J. Newman, and J.D. Beggs. 1998. Protein-RNA interactions in the U5 snRNP of Saccharomyces cerevisiae. RNA 4: 1675-1686.

Dreyfuss, G., M.J. Matunis, S. Pinol-Roma, and C.G. Burd. 1993. hnRNP proteins and the biogenesis of mRNA. Annu. Rev. Biochem. 62: 289-321.

Eldridge, A.G., Y. Li, P.A. Sharp, and B.J. Blencowe. 1999. The SRm160/300 splicing coactivator is required for exon-enhancer function. Proc. Natl. Acad. Sci. 96: 6125-6130.

Hentze, M.W. and A.E. Kulozik. 1999. A perfect message: RNA surveillance and nonsense-mediated decay. Cell 96: 307-310.

Hirose, Y. and J.L. Manley. 1998. RNA polymerase II is an essential mRNA polyadenylation factor. Nature 395: 93-96.

Hirose, Y., R. Tacke, and J.L. Manley. 1999. Phosphorylated RNA polymerase II stimulates pre-mRNA splicing. Genes \& Dev. 13: 1234-1239.

Hodges, P.E., S.P. Jackson, J.D. Brown, and J.D. Beggs. 1995. Extraordinary sequence conservation of the PRP8 splicing factor. Yeast 11: 337-342.

Izaurralde, E. and S. Adam. 1998. Transport of macromolecules between the nucleus and the cytoplasm. RNA 4: 351-364.

Izaurralde, E., A. Jarmolowski, C. Beisel, I.W. Mattaj, G. Dreyfuss, and U. Fischer. 1997. A role for the M9 transport signal of hnRNP A1 in mRNA nuclear export. J. Cell. Biol. 137: 2735.

Konarska, M.M. and P.A. Sharp. 1987. Interactions between small nuclear ribonucleoprotein particles in formation of spliceosomes. Cell 49: 763-774.

Lall, S., H. Francis-Lang, A. Flament, A. Norvell, T. Schupbach, and D. Ish-Horowicz. 1999. Squid hnRNP protein promotes apical cytoplasmic transport and localization of Drosophila pair-rule transcripts. Cell 98: 171-180.

Legrain, P. and M. Rosbash. 1989. Some cis- and trans-acting mutants for splicing target pre-mRNA to the cytoplasm. Cell 57: 573-583.

Li, S., D. Leonard, and M.F. Wilkinson. 1997. T cell receptor (TCR) mini-gene mRNA expression regulated by nonsense codons: a nuclear-associated translation-like mechanism. $J$. Exp. Med. 185: 985-992.

Luo, H.R., G.A. Moreau, N. Levin, and M.J. Moore. 1999. The 
human Prp8 protein is a component of both U2- and U12dependent spliceosomes. RNA 5: 893-908.

Luo, M.J. and R. Reed. 1999. Splicing is required for rapid and efficient mRNA export in metazoans. Proc. Natl. Acad. Sci. 96: 14937-14942.

MacMillan, A.M., C.C. Query, C.R. Allerson, S. Chen, G.L. Verdine, and P.A. Sharp. 1994. Dynamic association of proteins with the pre-mRNA branch region. Genes \& Dev. 8: 3008 3020.

Maquat, L.E. 1995. When cells stop making sense: Effects of nonsense codons on RNA metabolism in vertebrate cells. RNA 1: 453-465.

-1996. Defects in RNA splicing and the consequence of shortened translational reading frames. Am. J. Hum. Genet. 59: 279-286.

Matsumoto, K., K.M. Wassarman, and A.P. Wolffe. 1998. Nuclear history of a pre-mRNA determines the translational activity of cytoplasmic mRNA. EMBO J. 17: 2107-2121.

McCracken, S., N. Fong, E. Rosonina, K. Yankulov, G. Brothers, D. Siderovski, A. Hessel, S. Foster, S. Shuman, and D.L. Bentley. 1997a. 5'-Capping enzymes are targeted to premRNA by binding to the phosphorylated carboxy-terminal domain of RNA polymerase II. Genes \& Dev. 11: 3306-3318.

McCracken, S., N. Fong, K. Yankulov, S. Ballantyne, G. Pan, J. Greenblatt, S.D. Patterson, M. Wickens, and D.L. Bentley. 1997b. The C-terminal domain of RNA polymerase II couples mRNA processing to transcription. Nature 385: 357-361.

Misteli, T. and D.L. Spector. 1999. RNA polymerase II targets pre-mRNA splicing factors to transcription sites in vivo. Mol. Cell 3: 697-705.

Moore, M.J. and C.C. Query. 1998. Uses of site-specifically modified RNAs constructed by RNA ligation. In RNA-protein interactions: A practical approach (ed. C.W.J. Smith), pp. 75-108. IRL Press, Oxford, UK.

Moore, M.J. and P.A. Sharp. 1992. Site-specific modification of pre-mRNA: The 2 '-hydroxyl groups at the splice sites. Science 256: 992-997.

Nagy, E. and L.E. Maquat. 1998. A rule for termination-codon position within intron-containing genes: When nonsense affects RNA abundance. Trends. Biochem. Sci. 23: 198-199.

Nakielny, S. and G. Dreyfuss. 1997. Nuclear export of proteins and RNAs. Curr. Opin. Cell. Biol. 9: 420-429.

Neugebauer, K.M. and M.B. Roth. 1997. Distribution of premRNA splicing factors at sites of RNA polymerase II transcription. Genes \& Dev. 11: 1148-1159.

Ohno, M. and Y. Shimura. 1996. A human RNA helicase-like protein, HRH1, facilitates nuclear export of spliced mRNA by releasing the RNA from the spliceosome. Genes \& Dev. 10: 997-1007.

Pasquinelli, A.E., R.K. Ernst, E. Lund, C. Grimm, M.L. Zapp, D. Rekosh, M.L. Hammarskjold, and J.E. Dahlberg. 1997. The constitutive transport element (CTE) of Mason-Pfizer monkey virus (MPMV) accesses a cellular mRNA export pathway. $E M B O ~ J$. 16: 7500-7510.

Query, C.C., M.J. Moore, and P.A. Sharp. 1994. Branch nucleophile selection in pre-mRNA splicing: Evidence for the bulged duplex model. Genes \& Dev. 8: 587-597.

Reyes, J.L., P. Kois, B.B. Konforti, and M.M. Konarska. 1996. The canonical GU dinucleotide at the 5 ' splice site is recognized by p220 of the U5 snRNP within the spliceosome. RNA 2: 213-225.

Rottman, F.M., J.A. Bokar, P. Narayan, M.E. Shambaugh, and R. Ludwiczak. 1994. N6-adenosine methylation in mRNA: Substrate specificity and enzyme complexity. Biochimie 76: $1109-1114$.
Saavedra, C., B. Felber, and E. Izaurralde. 1997. The simian retrovirus-1 constitutive transport element, unlike the HIV-1 RRE, uses factors required for cellular mRNA export. Curr. Biol. 7: 619-628.

Schaal, T.D. and T. Maniatis. 1999. Selection and characterization of pre-mRNA splicing enhancers: Identification of novel SR protein-specific enhancer sequences. Mol. Cell. Biol. 19: $1705-1719$.

Schwer, B. and C.H. Gross. 1998. Prp22, a DExH-box RNA helicase, plays two distinct roles in yeast pre-mRNA splicing. EMBO I. 17: 2086-2094.

Siatecka, M., J.L. Reyes, and M.M. Konarska. 1999. Functional interactions of Prp8 with both splice sites at the spliceosomal catalytic center. Genes \& Dev. 13: 1994-2004.

Sontheimer, E.J. 1994. Site-specific RNA crosslinking with 4-thiouridine. Mol. Biol. Rep. 20: 35-44.

Teigelkamp, S., A.J. Newman, and J.D. Beggs. 1995. Extensive interactions of PRP8 protein with the $5^{\prime}$ and $3^{\prime}$ splice sites during splicing suggest a role in stabilization of exon alignment by U5 snRNA. EMBO I. 14: 2602-2612.

Thermann, R., G. Neu-Yilik, A. Deters, U. Frede, K. Wehr, C. Hagemeier, M.W. Hentze, and A.E. Kulozik. 1998. Binary specification of nonsense codons by splicing and cytoplasmic translation. EMBO J. 17: 3484-3494.

Umen, J.G. and C. Guthrie. 1995. Prp16p, Slu7p, and Prp8p interact with the $3^{\prime}$ splice site in two distinct stages during the second catalytic step of pre-mRNA splicing. RNA 1: 584-597.

Visa, N., A.T. Alzhanova-Ericsson, X. Sun, E. Kiseleva, B. Bjorkroth, T. Wurtz, and B. Daneholt. 1996. A pre-mRNA-binding protein accompanies the RNA from the gene through the nuclear pores and into polysomes. Cell 84: 253-264.

Wagner, J.D., E. Jankowsky, M. Company, A.M. Pyle, and J.N. Abelson. 1998. The DEAH-box protein PRP22 is an ATPase that mediates ATP-dependent mRNA release from the spliceosome and unwinds RNA duplexes. EMBO I. 17: 29262937.

Wyatt, J.R., E.J. Sontheimer, and J.A. Steitz. 1992. Site-specific crosslinking of mammalian U5 snRNP to the $5^{\prime}$ splice site prior to the first step of premessenger RNA splicing. Genes \& Dev. 6: 2542-2553.

Zahler, A.M., W.S. Lone, J.A. Stalk, and M.B. Roth. 1992. SR proteins: A conserved family of pre-mRNA splicing factors. Genes \& Dev. 6: 837-847.

Zhang, J., X. Sun, Y. Qian, J.P. LaDuca, and L.E. Maquat. 1998a. At least one intron is required for the nonsense-mediated decay of triosephosphate isomerase mRNA: A possible link between nuclear splicing and cytoplasmic translation. Mol. Cell. Biol. 18: 5272-5283.

Zhang, J., X. Sun, Y. Qian, and L.E. Maquat. 1998b. Intron function in the nonsense-mediated decay of $\beta$-globin mRNA: Indications that pre-mRNA splicing in the nucleus can influence mRNA translation in the cytoplasm. RNA 4: 801-815. 


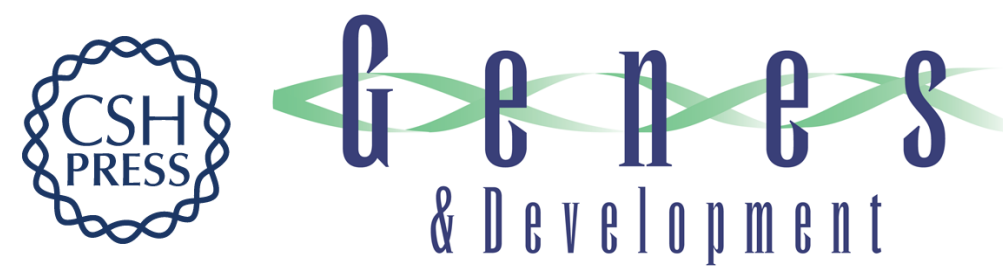

\section{Pre-mRNA splicing alters mRNP composition: evidence for stable association of proteins at exon-exon junctions}

Hervé Le Hir, Melissa J. Moore and Lynne E. Maquat

Genes Dev. 2000, 14:

Access the most recent version at doi:10.1101/gad.14.9.1098

References

This article cites 62 articles, 40 of which can be accessed free at: http://genesdev.cshlp.org/content/14/9/1098.full.html\#ref-list-1

License

Email Alerting

Receive free email alerts when new articles cite this article - sign up in the box at the top Service right corner of the article or click here.

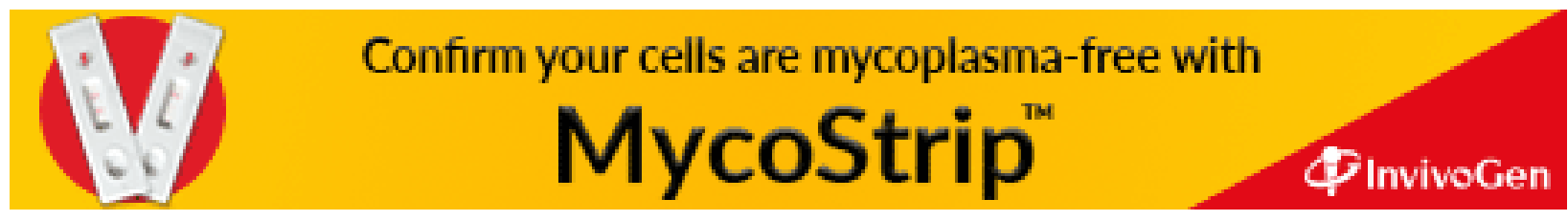

